\title{
A NOVEL FAULT TREE ANALYSIS APPROACH TO INVESTIGATE UNCOMMON ACCIDENTS IN QUARRIES: A CASE STUDY.
}

\author{
D. LIPPIELLO, G. ALFARO DEGAN \& M. PINZARI \\ Department of Engineering, University of Roma Tre, Rome, Italy.
}

\begin{abstract}
Quarrying companies are increasingly involved in developing effective Occupational Health and Safety Management Systems (OHSMS) to protect both their own staff and all those collaborating with their organization. The adoption of schemes such as BS OHSAS 18001:2007 helps the company to comply with legal requirements and serves the personnel both by raising awareness of the potential adverse consequences to which they are exposed (i.e., the risk of accident and potential occupational illness), and by limiting and managing the risk of occupational hazards.

Since the quarry environment presents many hazardous factors, various approaches to monitor and control their effects are required; among them the choice of OHS risk assessment methods and the approach to accident investigation being the most crucial. This paper refers to a case study of an unusual accident which occurred in an Italian quarry recently. The analysis aims to identify and describe the true course of events, as well as to analyse the direct causes and contributing factors of the accident, the main objective being to identify best practices in risk reducing measures in order to prevent similar accidents occurring in the future. Initially a deductive approach is taken using the Fault Tree Analysis (FTA) method. This is then improved by integrating a Management Oversight and Risk Tree (MORT) technique and Multiple Cause Systems Oriented Incident Investigation (MCSOII). The proposed analysis is finally utilized to design and define procedures to manage these particular activities.

Keywords: accident investigation, Fault Tree Analysis, MCSOII, MORT, quarry.
\end{abstract}

\section{INTRODUCTION}

Quarrying companies are committed to managing hazards and reducing risks in order to make their worksites as safe as possible. Better performance and ongoing compliance with industry best practices are often connected with the adoption of standards such as BS OHSAS 18001 [1], which constitute a framework for an Occupational Health and Safety Management System (OHSMS) [2]. Such standards can help an organization to put in place the policies, procedures and controls needed to achieve the best possible working conditions and health and safety in the workplace [3-5], in alignment with internationally recognized best practices also taking into account their effects on the surrounding environment [6]. Nevertheless, occupational health and safety management is a long-term commitment requiring continual reappraisal and improvement [7]. In order to achieve this goal an iterative four-step management method is generally used, the so called Plan-Do-Check-Act cycle (PDCA). This approach, based on the scientific method, may be expressed as "hypothesis-experimentevaluation" or as "plan-do-check", and is used in business to control and continually improve processes. Dr. Deming himself, the man who popularised the method, continually emphasized the need for iteration towards an improved system, thus any PDCA cycle should be repeatedly implemented in spirals of increasing system knowledge, such that each cycle improves upon the previous one. Deming later adopted the acronym PDSA, changing Check (C) to Study (S), which emphasizes the importance of analysing the results obtained empirically and comparing them with the predictions and objectives, and thus indicating whether further action is required to improve the process. This concept may be applied through the 
use of internal audits, incident investigations and corrective actions, and may be further strengthened by applying the same methodology to the techniques and methods adopted in the analysis of accidents $[8,9]$.

Since from this perspective accident analysis is crucial to safety management, some relevant data from the INAIL database are examined in the following section regarding accidents in the Italian extractive industry over the period from 2012 to 2016. INAIL, the Italian National Institute for Insurance against Accidents at Work, is a public non-profit entity safeguarding workers against injuries and occupational diseases, which particularly concerned with protection of those performing hazardous jobs.

Table 1 summarizes accidents, involving physical injuries and deaths, which occurred while personnel were carrying out Italian extractive activities between 2012 and 2016 and indicates whether or not the accidents occurred on site.

Table 2 below presents a more detailed analysis of the data referring to the accidents which took place at the worksite, indicating the circumstances under which these accidents occurred.

Accidents due to contact between equipment and high voltage power lines are of particular interest for the research presented in this paper; consequently the data contained in line 1 of table 2 are examined in greater detail in table 3.

Table 1: Number of accidents related to Italian quarries and mines (2012-2016).

\begin{tabular}{llllll}
\hline & \multicolumn{2}{l}{ Year of occurrence } \\
\cline { 2 - 6 } ACCIDENT Location & 2012 & 2013 & 2014 & 2015 & 2016 \\
\hline Worksite & 651 & 576 & 503 & 419 & 428 \\
En route to or from site & 96 & 110 & 107 & 112 & 111 \\
\hline
\end{tabular}

Table 2: Circumstances of accidents at Italian quarry and mine sites (2012-2016).

\begin{tabular}{|c|c|c|c|c|c|}
\hline \multirow[b]{2}{*}{ Circumstances } & \multicolumn{5}{|c|}{ Year of occurrence } \\
\hline & 2012 & 2013 & 2014 & 2015 & 2016 \\
\hline $\begin{array}{l}\text { Contact with electrical current, high temperatures, } \\
\text { or dangerous substances }\end{array}$ & 45 & 50 & 54 & 59 & 38 \\
\hline Victim drowned, buried, or emerged into gas & 1 & 0 & 0 & 2 & 0 \\
\hline $\begin{array}{l}\text { Victim striking against a stationary object (victim } \\
\text { in movement vertically or horizontally) }\end{array}$ & 139 & 132 & 110 & 88 & 90 \\
\hline Victim struck by or collided with a moving object & 116 & 88 & 74 & 51 & 53 \\
\hline $\begin{array}{l}\text { Contact with sharp, pointed, hard, or abrasive } \\
\text { materials }\end{array}$ & 161 & 126 & 126 & 100 & 89 \\
\hline Crushed while caught in or between objects & 51 & 45 & 42 & 31 & 41 \\
\hline $\begin{array}{l}\text { Accident due to physical or mental effort on the } \\
\text { part of the victim }\end{array}$ & 88 & 96 & 58 & 38 & 47 \\
\hline $\begin{array}{l}\text { Victim attacked by animal or another human being } \\
\text { (bitten, kicked, etc.) }\end{array}$ & 5 & 4 & 1 & 2 & 2 \\
\hline Circumstances yet to be determined & 45 & 35 & 38 & 48 & 68 \\
\hline Total & 651 & 576 & 503 & 419 & 428 \\
\hline
\end{tabular}


Table 3: Circumstances of accidents with electrical or chemical causes in Italian quarries and mines (2012-2016).

\begin{tabular}{llllll}
\hline & \multicolumn{3}{l}{ Year of occurrence } & & \\
\cline { 2 - 6 } Circumstances & 2012 & 2013 & 2014 & 2015 & 2016 \\
\hline $\begin{array}{l}\text { Contact with dangerous substances via the digestive } \\
\text { system; substances swallowed or eaten }\end{array}$ & 3 & 8 & 2 & 0 \\
$\begin{array}{l}\text { Contact with object that is hot or red-hot or with } \\
\text { naked flame }\end{array}$ & 7 & 5 & 2 & 1 & 4 \\
$\begin{array}{l}\text { Contact with object or environment which is cold or } \\
\text { freezing }\end{array}$ & 7 & 2 & 4 & 3 \\
$\begin{array}{l}\text { Direct contact with electrical current } \\
\text { Indirect contact with electricity via arcing or light- }\end{array}$ & 0 & 1 & 0 & 0 & 0 \\
$\begin{array}{l}\text { ning strike } \\
\text { Contact with dangerous substances via skin or eyes }\end{array}$ & 14 & 16 & 32 & 25 & 7 \\
$\begin{array}{l}\text { Contact with dangerous substances via nose, mouth } \\
\text { or inhalation }\end{array}$ & 15 & 13 & 9 & 26 & 21 \\
$\begin{array}{l}\text { Direct contact with electricity: electrical current } \\
\text { passing through body }\end{array}$ & 0 & 0 & 1 & 0 & 1 \\
$\begin{array}{l}\text { Not specified } \\
\text { Total }\end{array}$ & 0 & 3 & 0 & 0 & 1 \\
\hline
\end{tabular}

With reference to the data regarding accidents from electrical causes (lines 4, 5 and 8 of table 3) we may consider electrical accidents as being uncommon events since they represent less than $3 \%$ of the total accidents reported by quarry companies. Nevertheless, the consequences may have an enormous impact on the workers exposed to such hazards.

In this paper one such accident is considered, which occurred at an Italian quarry site in 2017. The 'study' phase of the PDSA cycle is implemented by means of a Fault Tree Analysis (FTA) approach aimed at identifying the direct causes and contributing factors to the accident. The final goal is to identify risk reducing measures in order to prevent similar accidents occurring in the future.

\section{MATERIALS AND METHODS}

A number of methods for accident investigation have been developed since 1980's [10]. In this paper a deductive approach is adopted as it would seem to be the most effective means of performing a root cause analysis to determine any events and conditions that contributed to the accident.

\subsection{Fault Tree Analysis (FTA)}

The main technique adopted is the Fault Tree Analysis (FTA), which is a top-down method for determining the causes (the 'basic events') of an undesired event, i.e., the accident (the so-called 'top event'). This technique was designed to perform accident investigations in industrial systems and mainly focuses on the reliability of technological components. The fault tree is a diagram that displays the various combinations of normal events, equipment 
failure, and environmental factors that may result in an accident. The undesired event appears as the top event, which is linked to the basic failure events by logic gates and event statements. A logic gate symbol can have one or more inputs, but only one output. The main logic gates are:

- the OR gate, which indicates that the output event A occurs if at least one of the input events occur.

- the AND gate, which indicates that the output event A occurs if all the input events occur simultaneously.

In a fault tree diagram, an intermediate event is shown inside a rectangle; whereas when the cause of failure cannot be developed any further the event is shown inside an oval, indicating that at this stage the top-down method has reached the 'basic event' (or 'root cause').

However, a solely FTA approach may result as being incomplete since it mainly highlights causes due to the failure of technological equipment without taking the human component into account in the failure of any semi-automatic or manual safety systems. The assessment of system failure would be unrealistic, both statistically and in terms of severity of consequences, without considering the human factor in the dynamics of accidents. Consequently, in order to address the human aspect, a Management Oversight and Risk Tree (MORT) approach is integrated into the methodology.

\subsection{Management Oversight and Risk Tree (MORT)}

The Management Oversight and Risk Tree (MORT) [11] was designed to provide a technique for the thorough investigation of occupational accidents and analysis of safety programs, which has been found to be an effective tool in improving safety in activities in which accident rates are already low. MORT is a systematic, logical decision tree which is capable of connecting and integrating a wide variety of safety concepts and is particularly useful in assessing human reliability to reduce the likelihood of error.

In the MORT the following definitions are used:

- incident, an event in which the barrier to an undesired flow of energy is inadequate or malfunctioning, without any harmful or untoward consequences;.

- accident, an undesired flow of energy or exposure to an environmental condition which results in harmful or untoward consequences.

Whenever a person or system might come into contact with a flow of energy or an environmental condition which could provoke injury or damage, isolation from such undesirable circumstances must be provided.

Four distinct elements should be taken into account in the development of a MORT based diagram:

- 1st element - may be considered as being the top event of the FTA and defines the general objective i.e., to prevent or safeguard against a potentially harmful flow of energy and environmental conditions (sources of danger);

- 2nd element - comprises any receiver people and systems which are potentially vulnerable to a potentially harmful flow of energy and environmental conditions; 
- 3rd element - constitutes the set of the possible malfunctions or lack of barriers and controls which is responsible for isolating the vulnerable receivers from the sources of danger;

- 4th element - consists in precursory events.

Having defined these four elements, the MORT analysis is performed by means of a preconceived tree structure (or generic tree), which is developed from the top downwards. When the appropriate segments of the tree have been completed, the path of cause and effect can easily be traced back through the tree (from a management oversight, to basic causes, contributory causes, and root causes).

\subsection{Multiple-Cause, Systems Oriented Incident Investigation (MCSOII)}

The Multiple-Cause, Systems Oriented Incident Investigation (MCSOII) technique was developed from the logical foundations of the FTA with some simplifications without information loss. After the facts have been gathered from the field, the analysis develops a chronological sequence of events leading up to the incident.

Therefore, similarly to other analysis techniques, a first attempt logical tree is used, at least for the initial phase, in order to determine the logical constraints of the analysis.

The event at the top of the tree (the top event) consists of damage to people or things or both; and in our case study refers to an injury due to contact with high voltage power lines. At the second level of the tree two different events are indicated as starting points for the development of the next subtree, or rather there are two possible causes which triggered the accident.

Each of the second level events is then developed into a detailed tree, answering the question: 'Why did this event occur?'.

This question is then repeated for each further event that is added progressively to the tree, until what are considered the 'root causes' have been reached at the base of the tree. In determining at which point to stop requires experience and good sense and, as in the Fault Tree Analysis, it is always possible to take the analysis to a further if deemed necessary.

When the tree has been completed, any additional information that has not been explicitly mentioned in the tree that may however be associated with possible causes is also reported at this stage, on condition that the analyst feels that it may have some bearing upon the case and that it is logically consistent with the overall picture.

The individual examination of each root cause prompts the formulation of a number of recommendations for pre-emptive measures which may be implemented to improve the current OHSMS. The MCSOII technique is particularly good at highlighting common causes of incidents and is normally applicable both to improve on-site OHSMS and to examine relevant incidents. Hence, this technique was considered particularly suitable for the analysis of the accident in question.

\subsection{Accident location}

The accident took place in a basalt granule quarry in the Lazio region of Italy. Basalt is extracted from the rock face using single row blasting; the quarried material is then loaded and transported by dumper truck to the processing yard where it is crushed and selected. The material is then sorted by means of a mobile screen plant with conveyor belt arms. In order to reduce time and costs the mobile screen plant is habitually moved to an area adjacent to 


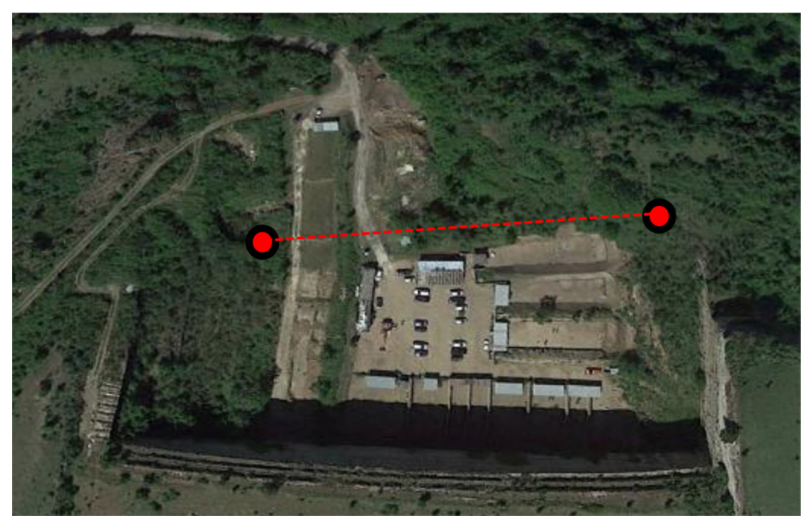

Figure 1: An aerial view of the quarry processing yard indicating the position of the high voltage cable and pylons in red.

where the material is being extracted. An aerial view of the quarry processing yard is shown in Fig. 1.

A high voltage $(\mathrm{HV})$ power line $(132 \mathrm{kV})$ crosses the quarry processing yard shown in Fig.1 in which the two pylons have been indicated with red dots and the red dashed line represents the HV power line between the two. The power line is at a height of between 7 and 8 metres above ground level. When the mobile screen plant (shown in Fig. 2) is not in use it is driven along the site road to the parking area crossing underneath the HV power line. The mobile plant is a versatile piece of machinery that is equipped with moveable conveyor belt arms. These may be extended to 12 metres in length in addition to being raised or lowered according to requirements of the task to be undertaken.

Figure 3 below shows a diagram of one of the pylons and the relative distances between the power lines and ground level, indicating that the minimum clearance is approximately 7 metres at the lowest point in the catenary curve of the lowest power line.

Should the mobile screen plant be driven back to the parking area with its conveyor belt arms in their vertical position, the arms would inevitably come into contact with the high voltage power line due to their height, thus triggering arcing and resulting in harmful

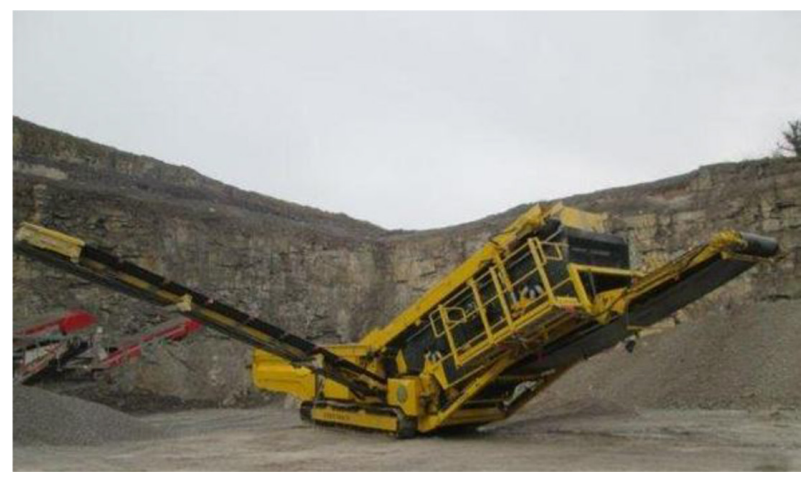

Figure 2: The mobile screen plant. 


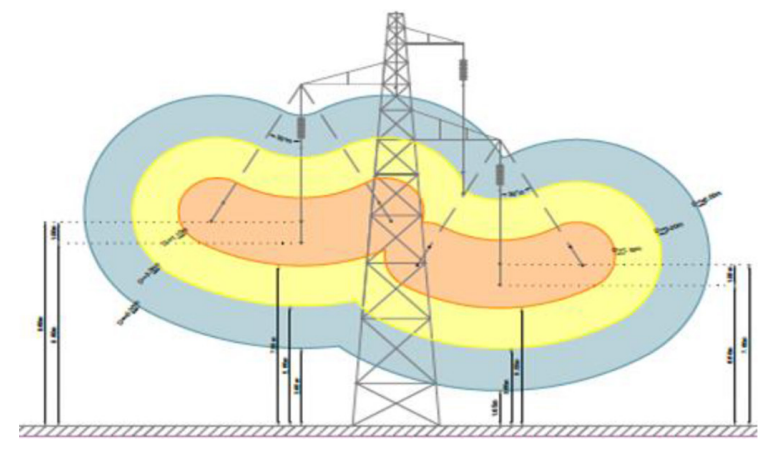

Figure 3: The pylon and distances from ground level.

consequences for the operator. As explained previously, a fault tree integrated with the MORT and MCSOII techniques is employed to define the causes of the accident.

\section{RESULTS}

The application of the method applied to the specific site, determined the following tree, which is divided into two different sheets, see Figs 4 and 5, in order to be better appreciated.

For a better understanding of the diagrams, the meanings attributed to the various nodes of the tree are clarified in the legend below.

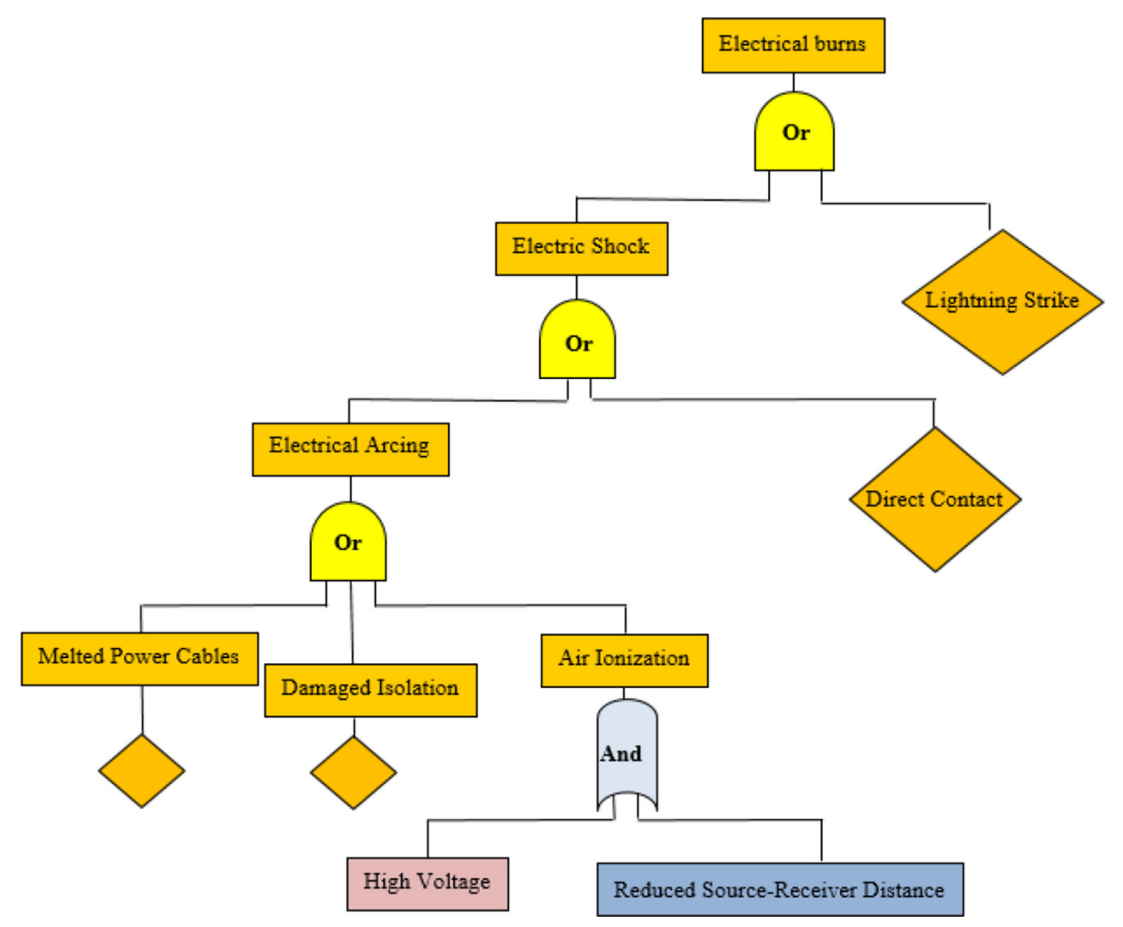

Figure 4: The integrated fault tree part 1. 


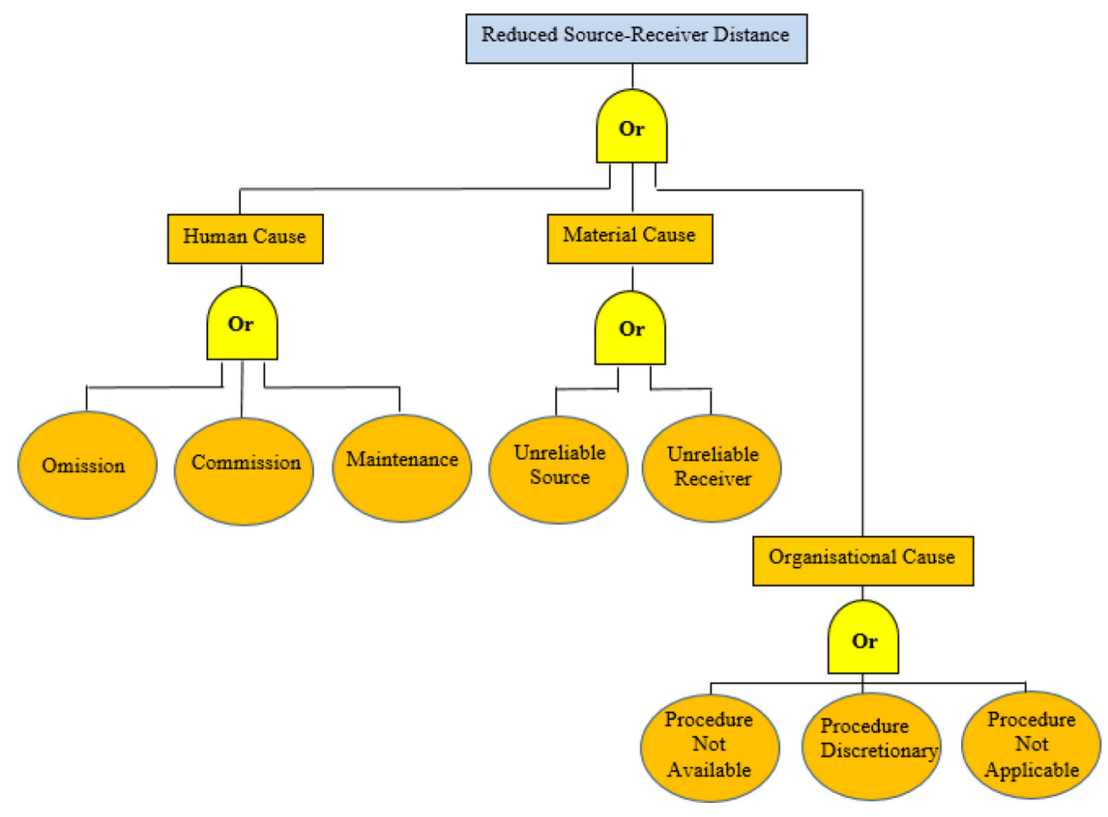

Figure 5: The integrated fault tree part 2.

\subsection{Glossary}

Electric Shock: electrical accident, possibly fatal, determined by artificial causes relating to electrical power;

Lightning Strike: electrical accident, possibly fatal, determined by natural causes (mainly atmospheric);

Electrical Arcing: electrical discharge which propagates through a conductive medium (in this case air) between two points with a high voltage across them;

Direct Contact: physical contact between a live electrical component or circuit and the receiver;

Melted Power Cables: damage due to the overheating of high voltage cables;

Insulator Damage: a reduction in the insulating qualities of the protective outer sheath of a high voltage power line (due to mechanical, meteorological causes etc.);

Air Ionization: electrical phenomenon in which a fluid (in this case air) is subject to an elevated potential gradient, consequently increasing the likelihood of its conducting electricity (see electrical arcing);

High Voltage: an elevated difference in electric potential between two components;

Presence of High Voltage Power Lines: HV (132 Kv) power lines in the area of interest;

Reduced Source-Receiver Distance: a reduction in the distance between the source (HV power line) and the receiver (the machinery in movement) such that it is less than the minimum distance required to guarantee the minimum safety levels;

Human Cause: an inappropriate or undesirable decision or behaviour which provokes a reduction (effective or potential) in the efficiency or levels of safety of a technical component or system; 
Material Cause: any deviation in the condition of a system, piece of equipment or component from its normal operating conditions;

Organisational Cause: the lack or inadequacy of operating instructions, procedures, or behavioural rules governing the various phases of the tasks to be performed.

\section{Human Causes}

In a non-automated context, that is a situation in which an operator interacts with machinery, human error plays a significant role and may be categorised in one or more of three distinct types of error:

- error of commission: the performance of an action which prevents the achievement of the goal;

- error of omission: the failure to perform an action which must be carried out in order to achieve the goal;

- error of maintenance: an error which increases the chance of damaging a component or system;

\section{Material Cause}

In an industrial context which includes various technological components, the material cause may usually be traced back to individual components malfunctioning.

Material causes may be classified as one of the following:

- Unreliable source: a deviation in the operating or design conditions of the source component, i.e., a deviation in the source of the potentially harmful flow of energy (noncompliance);

- Unreliable receiver: a deviation in operating or design conditions of the receiver component, i.e., the component at risk of receiving the potentially harmful flow of energy from the source.

\section{Organisational Cause}

Any given activity that presupposes the interaction between operator and machine or system is normally organised by deciding upon a particular procedure to be performed, i.e., the management issues the operator with a sequence of instructions to be followed in addition to specifying the times and places that they are to be carried out. Organisational causes may be categorised as:

- Procedure not available: the instructions to be performed are not available to the operator because they are not provided by the organisation, or they are not distributed properly to the operator, or else they are not available for operator to use;

- Procedure not applicable: the instructions to be performed do not correspond to the real operating conditions and, as a result of this disparity between the instructions and reality, renders the procedure inapplicable.

- Procedure discretionary: although the instructions to be performed are issued to the operator, they are open to interpretation or their application is facultative. In this case, despite also being an error of omission on the part of the operator (see 'error of omission' above), it entails a procedural shortfall on the part of the management as it disregards the fundamental requirement to apply the procedure itself. 


\section{DISCUSSION}

The logical process developed above may be used to identify a series of root causes, which, however, must then be considered in relation to the specific context of the accident in question. Thus in this phase, all of the potential root causes of the accident are examined separately in order to eliminate those which are irrelevant. As with all the steps in this approach to accident analysis, the rationale for keeping or discarding any root cause should be supported with documentary evidence.

In this case, the event was due to the presence of the high voltage (HV) power line (132 $\mathrm{KV}$ ). The radio-controlled mobile screen plant, while being moved to the parking area, exceeded the safe levels of proximity to the power line. This reduction in distance between the moving plant and the HV power line triggered electrical arcing through the ionisation of the aeriform fluid between them.

Tracing back through the tree, the action of exceeding the safe proximity levels are due to three different types of causes: material causes, human causes and organisational causes.

Starting from material causes, i.e., those relating to the malfunctioning of any technical components involved (source and receiver), there was no reason to believe that the mobile screen plant (receiver) displayed any instances of unreliability or had any problems responding to its controls immediately prior to the accident. Likewise, with regard to technical problems at the source component (the HV power lines), no report of malfunctioning appears to have been documented by the electricity network operator. Moreover, no extraordinary meteorological events which might have damaged the network were reported in the period prior to the accident.

Therefore, for the reasons given above, material causes, i.e., those owing to machinery breakdown or power line malfunctioning, are to be excluded with reasonable certainty.

The analysis of human causes appears to be more complex. While on the one hand the error of maintenance seems to be out of context since the mobile screen plant had been functioning perfectly during manoeuvres, errors of commission and omission on the part of the operator appear to be more relevant. By definition, an error of commission relates to plant unsatisfactory performance after operators have received adequate instructions. And this is certainly applicable if electrical arcing is triggered when the minimum clearance distance below a high voltage power line is breached due to the extendible arm of the plant not having been retracted, as occurred in this case study. On the other hand, an error of omission overlaps the above case if the operator has neglected to apply the company's Standard Operating Procedure (SOP) in which details of the correct course of action are provided.

In general, therefore, the two types of human error are admissible when determining root causes, on condition that the existence of company's SOP is confirmed, and that the SOP clearly states the correct procedure required to manoeuvre the mobile screen plant to the parking area.

Whether or not the procedure in question is present directly introduces the analysis of a further possible root cause, i.e., that of organisational causes. As explained above, organisational causes may be classified into three categories (procedure not available, procedure not applicable, and procedure discretionary). The company's compliance with the binding legislation demonstrates some care and attention taken on the part of the company management towards the activity of moving the mobile plant to the parking area and towards indicating the presence of safety hazards which may be encountered while this activity is being performed. In fact the company has a risk assessment document regarding minimum safe clearance distances from HV power lines pursuant to Legislative Decree 81/08 in accordance with the technical dictates of the Italian standard 'Norma CEI 11-27 del 2014'. This document states 
the need to ensure that the extendible parts of the plant are not less than 1.10 metres from the HV power lines, and therefore both the hypothesis of 'procedure discretionary' and that of 'procedure not applicable' may be excluded.

The 'procedure not available', i.e., the lack of a dedicated procedure to regulate the execution of the activity in question, is more relevant.

The term 'procedure', is intended to mean a formalized sequence of individual elementary operations with the allocation of individual tasks to specific persons or job categories; the same definition may be found in the international standard BS OHSAS 18001: 07. The employer must record the assignment of procedural responsibilities such that the contents of the procedures, the act of communicating of the procedures, and the acknowledgment of the receipt of the procedures on the part of the operators may be verified. In this respect, the evidence gathered does not allow the root cause of 'procedure not available' to be excluded: no operating procedure was found concerning the execution of the activity in question and, there is no indication to date that such procedural instructions are available in the company.

In the light of these findings, it is possible to trace the accident to two distinct, but related, root causes. The lack of a specific formalized procedure, which inevitably also compromised the availability of the same (in spite of management's requests to respect the correct operating practices), compromised the safety of the activity; however, the failure to retract the arm of the mobile screen plant was also an evident error of commission.

\section{CONCLUSIONS}

The case analysed here is particularly interesting in that it highlights two of the most significant aspects with regard to safety management in an industrial production context: human behaviour and the definition of operative procedures. In the event under investigation the two factors are clearly inextricably linked and hence the one should not be examined in isolation from the other.

In fact the implementation of procedures serves to formalize not only the workers' roles and responsibilities, but also the adoption of organizational measures and techniques which limit the likelihood of such an accident occurring in the first place. In this case study, for example, the procedure should have provided a specified area for machinery manoeuvres, including a place for parking and a signalling system on the ground indicating whether the arm of the mobile screen plant is extended or retracted. At the same time, human error may be further reduced through the adoption of incentives which induce workers to adhere to the existing procedure. A possible solution might consist in assigning one worker the role of both ensuring that his or her colleagues follow the correct procedure, and rewarding those who carry out the tasks correctly.

\section{REFERENCES}

[1] Alfaro Degan, G., Lippiello, D. \& Pinzari, M., Occupational health and safety management systems: comparison between BS OHSAS 18001: 2007 and Italian Decree 81/2008. WIT Transactions on Biomedicine and Health, Vol. 14, WIT Press, pp. 401409, 2009. https://doi.org/10.2495/EHR090391

[2] Joy, J., Occupational safety risk management in Australian mining. Occupational Medicine, 54(5), pp. 311-315, 2004. https://doi.org/10.1093/occmed/kqh074 
[3] Ersoy, M., Eleren, A. \& Şimşek, S., Work safety and health based process improvement analysis by using FMEA and application in marble quarry works. Madencilik, 48(3), pp. 19-32, 2009.

[4] Bersano, D., Cigna, C., Patrucco, M., Pession, J.M., Ariano, P.F., Prato, S., Romano, R. \& Scioldo, G., Extractive activities start up and management: a computer assisted specially developed 'prevention through design' approach. International Journal of Mining, Reclamation and Environment, 24(2), pp. 124-137, 2010.

https://doi.org/10.1080/17480930903003680

[5] Yarahmadi, R., Bagherpour, R. \& Khademian, A., Safety risk assessment of Iran's dimension stone quarries (Exploited by diamond wire cutting method). Safety Science, 63, pp. 146-150, 2014.

https://doi.org/10.1016/j.ssci.2013.11.003

[6] Alfaro Degan, G., Lippiello, D., Picciolo, L. \& Pinzari, M., Visual impact from quarrying activities: a case study for planning the residential development of surrounding areas. WIT Transactions on Ecology and the Environment, Vol. 181, WIT Press, pp. 125-136, 2014.

https://doi.org/10.2495/EID140111

[7] Khan, F.I. \& Haddara, M.M., Risk-based maintenance (RBM): a quantitative approach for maintenance/inspection scheduling and planning. Journal of Loss Prevention in the Process Industries, 16(6), pp. 561-573, 2003. https://doi.org/10.1016/j.jlp.2003.08.011

[8] Komljenovic, D., Groves, W.A. \& Kecojevic, V.J., Injuries in U.S. mining operations: a preliminary risk analysis. Safety Science, 46(5), pp. 792-801, 2008. https://doi.org/10.1016/j.ssci.2007.01.012

[9] Sari, M., Duzgun, H.S.B., Karpuz, C. \& Selcuk, A.S., Accident analysis of two Turkish underground coal mines. Safety Science, 42(8), pp. 675-690, 2004. https://doi.org/10.1016/j.ssci.2003.11.002

[10] Rausand, M. \& Høyland, A. Introduction, in System Reliability Theory: Models, Statistical Methods, and Applications, 2nd edn., John Wiley \& Sons, Inc., Hoboken, NJ, USA, 1994.

https://doi.org/10.1002/9780470316900.ch1BBS

[11] Johnson, W.J., MORT Safety Assurance System. Dekker, New York, USA, 1980. 